\title{
Trabeculectomy combined with cataract extraction: a follow-up study
}

\author{
R. S. EDWARDS \\ From the Birmingham and Midland Eye Hospital, Church Street, Birmingham B3 2NS
}

SUMMARY Fifty-nine eyes undergoing combined cataract extraction and trabeculectomy were studied. The follow-up period ranged from 6 months to 2 years. The visual outcome and postoperative control of intraocular pressure have been compared in chronic open-angle, chronic closed-angle, and secondary glaucoma. Good results were obtained in both primary open- and closed-angle glaucoma, but not in secondary glaucoma.

The aim of this retrospective study was to assess the outcome of combined cataract extraction and trabeculectomy, and to determine whether it is a safe, effective procedure for patients in whom cataract and glaucoma coexist.

Trabeculectomy has been shown to be a safe, effective operation in both open- and closed-angle glaucoma ${ }^{12}$ and to a lesser extent in secondary glaucoma. ${ }^{3}$ A small study by Thyer and Wilson ${ }^{4}$ reported encouraging results when trabeculectomy was combined with cataract extraction for glaucoma patients with lens opacities. Further follow-up studies $^{56}$ confirmed the efficacy of this procedure, but numbers were small in the first study, and the period of follow-up was only 3 months in the second.

\section{Material and methods}

This paper reports the operative and follow-up findings in 47 patients ( 59 eyes) operated on between April 1974 and June 1978 at the Birmingham and Midland Eye Hospital by consultant staff and junior staff in training. The 59 eyes have been followed up for a minimum of 6 months; of these, 51 have been followed up for 12 months and 28 for 2 years. Most of the patients were over the age of 60 years (age range 23-87 years; mean age 69 years).

Three types of glaucoma were studied; primary open-angle glaucoma, chronic closed-angle glaucoma, and secondary glaucoma (Table 1). Preoperative assessments of glaucoma control (Table 2) and visual function were compared with those obtained postoperatively.

Correspondence to Mr R. S. Edwards.
Table 1 Breakdown of preoperative diagnosis

\begin{tabular}{ll}
\hline Diagnostic category & No. of eyes \\
\hline Primary open-angle glaucoma & 29 \\
Chronic closed-angle glaucoma & $19^{*}$ \\
Secondary glaucoma & $11^{\dagger}$ \\
Total & 59
\end{tabular}

*Peripheral iridectomy previously performed in 7; angle closure from a congenital angle anomaly in 2 . †Nine eyes with uveitis, 1 with neovascular glaucoma, and 1 with malignant glaucoma.

Table 2 Breakdown of preoperative therapy and control

\begin{tabular}{lll}
\hline Preoperative therapy & Controlled & Not \\
\hline No therapy & 0 & 5 \\
Topical medication only & 7 & 9 \\
$\begin{array}{l}\text { Topical medication + carbonic } \\
\text { anhydrase inhibitors }\end{array}$ & 9 & 29 \\
Total & 16 & 43 \\
\hline
\end{tabular}

SURGICAL PROCEDURE

The majority of operations were performed under general anaesthesia. After a large conjunctival flap had been reflected towards the limbus the superficial scleral flap for trabeculectomy, as described by Watson, ${ }^{7}$ was first prepared. A limbal groove was then extended on each side. 8-0 virgin silk sutures were preplaced in the section and superficial scleral flap prior to excising the deep scleral lamella and completing the section. A peripheral iridectomy was performed adjacent to the trabeculectomy site, followed by cataract extraction and wound closure. A subconjunctival steroid injection was given in 47 out of the 59 eyes. 


\section{Results}

The immediate and late postoperative complications and the visual outcome have been detailed in Tables 3-6. The control of glaucoma in each diagnostic category has been illustrated in Figs. 1-3. Comparisons of preoperative and postoperative glaucoma control are shown in Tables 7 and 8 , and overall glaucoma control is summarised in Table 9

Table 3 Intraoperative complications

\begin{tabular}{ll}
\hline Complication & No. of eyes \\
\hline Capsule rupture & $5(8.5 \%)$ \\
Vitreous loss & $2(3.4 \%)$ \\
\hline
\end{tabular}

Table 4 Immediate postoperative complications

\begin{tabular}{lc}
\hline Complication & No. of eyes \\
\hline Hyphaema & $15(25 \%)$ \\
Ocular hypertension & $11(18.6 \%)$ \\
Flat anterior chamber & $4(6.8 \%)$ \\
Severe uveitis & $6(10.2 \%)$ \\
Iris prolapse & $1(1.7 \%)$ \\
Infection & 0 \\
\hline
\end{tabular}

Table 5 Late postoperative complications

\begin{tabular}{ll}
\hline Complication & No. of eyes \\
\hline Retinal detachment & $1(1 \cdot 7 \%)$ \\
Bullous keratopathy & 0 \\
Neovascular glaucoma & $1(1 \cdot 7 \%)$ \\
Sympathetic ophthalmia & 0 \\
Endophthalmitis & 0 \\
Phthisis bulbi & $3 *(5 \cdot 1 \%)$ \\
\hline
\end{tabular}

*All these eyes had secondary glaucoma.

Table 6 Visual results: preoperative visual acuity compared with that obtained 6 months postoperatively

\begin{tabular}{lccccc}
\hline Total & & \multicolumn{4}{c}{ Diagnostic glaucoma group } \\
\hline Corr. VA & Preop. & Postop. & Open & Closed & Secondary \\
\hline $6 / 5-6 / 12$ & $0 \%$ & $49 \%$ & $48 \%$ & $59 \%$ & $36 \%$ \\
$6 / 18-6 / 36$ & $25 \%$ & $17 \%$ & $17 \%$ & $15 \%$ & $18 \%$ \\
$6 / 60-C F$ & $29 \%$ & $17 \%$ & $28 \%$ & $5 \%$ & $9 \%$ \\
HM-PL & $46 \%$ & $10 \%$ & $7 \%$ & $11 \%$ & $18 \%$ \\
NPL & $0 \%$ & $7 \%$ & $0 \%$ & $10 \%$ & $18 \%$ \\
Total no & 59 & 59 & 29 & 19 & 11 \\
of eyes & & & & &
\end{tabular}

VA $=$ visual acuity. $C F=$ counting fingers. $H M=$ hand movements . PL $=$ perception of light. NPL $=$ no perception of light. (control has been defined as an intraocular pressure of less than $23 \mathrm{mmHg}$ ).

\section{ASTIGMATISM}

The mean value for the 29 eyes obtaining $6 / 12$ vision or better was 1.96 dioptres. Similar values were obtained for patients with a lower corrected acuity. In no patient was the degree of astigmatism so high as to affect the visual outcome.

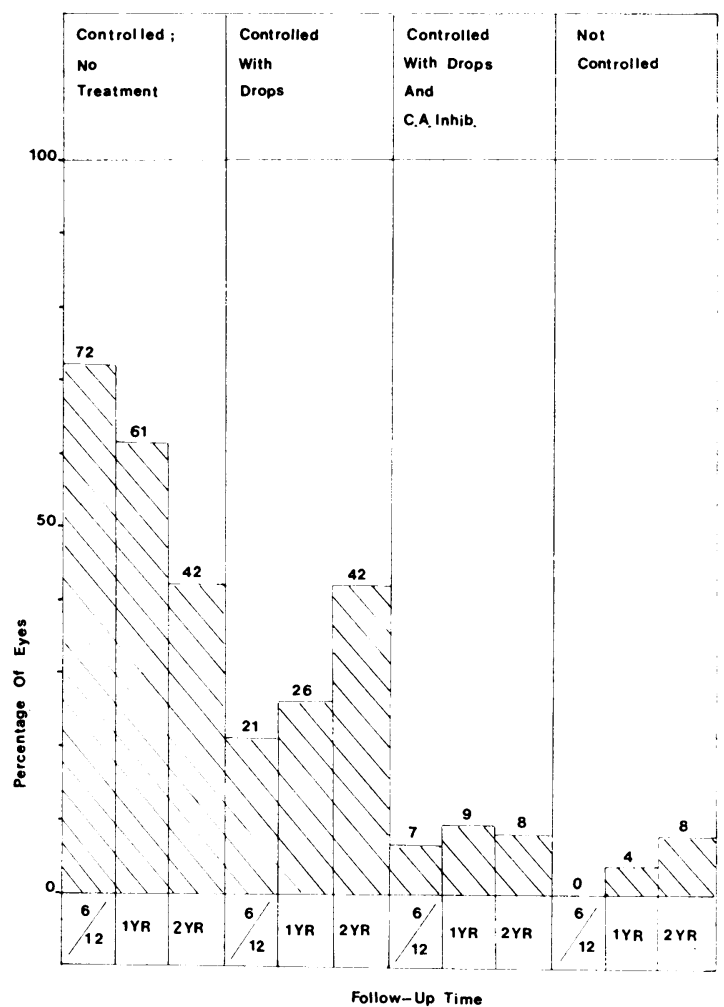

Fig. 1 Primary open-angle glaucoma: control of intraocular pressure after surgery. 29/29 Eyes followed up for 6 months. 23/29 Eyes followed up for 12 months. $14 / 29$ Eyes followed up for 2 years.

Table 7 Overall postoperative glaucoma control for eyes controlled preoperatively

\begin{tabular}{lccc}
\hline \multirow{2}{*}{ Postop. control } & \multicolumn{3}{l}{ Follow-up } \\
\cline { 2 - 4 } & $6 / 12$ & $1 y r$ & $2 y r$ \\
\hline No treatment & $89 \%$ & $82 \%$ & $50 \%$ \\
Drops \pm CA inhibitor & $11 \%$ & $18 \%$ & $50 \%$ \\
No control or phthisis & $0 \%$ & $0 \%$ & $0 \%$ \\
Total no. of eyes & 16 & 11 & 6 \\
\hline
\end{tabular}

$\mathbf{C A}=$ carbonic anhydrase. 


\section{Discussion}

INTR AOPER ATIVE COMPLICATIONS

Two eyes $(3.4 \%)$ lost vitreous during surgery; one of these eyes had previously had an iridencleisis operation. This rate is in keeping with that expected to complicate an intracapsular extraction (up to $3 \%$ quoted by Duke-Elder ${ }^{8}$ ). Capsule rupture

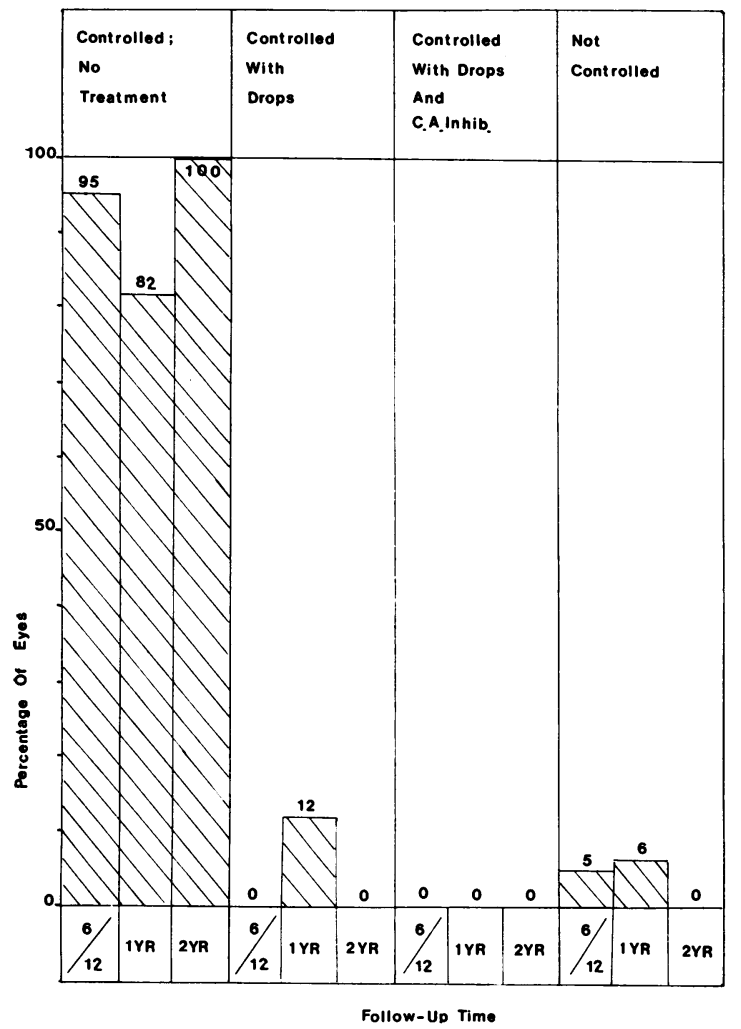

Fig. 2 Primary closed-angle glaucoma: control of intraocular pressure after surgery. 19/19 Eyes followed up for 6 months. 17/19 Eyes followed up for 12 months. 7/19 Eyes followed up for 2 years.

Table 8 Overall postoperative glaucoma control for eyes not controlled preoperatively

\begin{tabular}{llll}
\hline \multirow{2}{*}{ Postop. control } & \multicolumn{2}{l}{ Follow-up } \\
\cline { 2 - 4 } & $6 / 12$ & $1 y r$ & $2 y r$ \\
\hline No treatment & $71 \%$ & $55 \%$ & $54.5 \%$ \\
Drops \pm CA inhibitor & $17 \%$ & $25 \%$ & $27.5 \%$ \\
No control or phthisis & $12 \%$ & $20 \%$ & $18 \%$ \\
Total no. of eyes & 43 & 40 & 22 \\
\hline
\end{tabular}

$\mathbf{C A}=$ carbonic anhydrase. occurred with 5 eyes (8.5\%). Two of these eyes had had previous glaucoma surgery, and all had been on pilocarpine therapy for a long period, resulting in a rigid pupil with posterior synechiae.

\section{IMMEDIATE POSTOPERATIVE}

COMPLICATIONS

The serious complications of wound dehiscence and

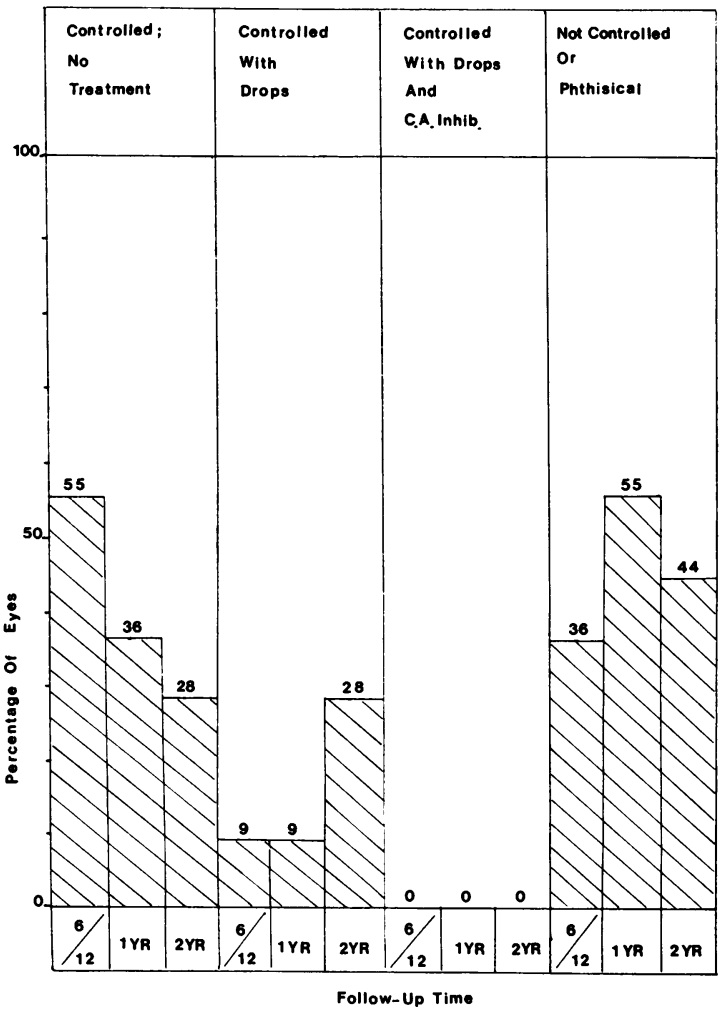

Fig. 3 Secondary glaucoma: control of intraocular pressure after surgery. 11/11 Eyes followed up for 6 months. 11/11 Eyes followed up for 12 months.

7/11 Eyes followed up for 2 years.

Table 9 Overall glaucoma control for all patients

\begin{tabular}{|c|c|c|c|}
\hline \multirow{2}{*}{ Control } & \multicolumn{3}{|l|}{ Follow-up } \\
\hline & $6 \mathrm{mths}$ & $1 y r$ & $2 y r$ \\
\hline $\begin{array}{l}\text { No treatment } \\
\text { Drops only } \\
\text { Drops }+ \text { CA } \\
\quad \text { inhibitor }\end{array}$ & $\left.\begin{array}{r}76.5 \% \\
12.0 \% \\
3.5 \%\end{array}\right\} 92 \%$ & $\left.\begin{array}{r}62.5 \% \\
17.5 \% \\
4.0 \%\end{array}\right\} 84 \%$ & $\left.\begin{array}{r}53.5 \% \\
28.5 \% \\
3.5 \%\end{array}\right\} 85.5 \%$ \\
\hline $\begin{array}{l}\text { No control } \\
\text { Phthisis }\end{array}$ & $\left.\begin{array}{l}5.0 \% \\
3.5 \%\end{array}\right\} 8.5 \%$ & $\left.\begin{array}{r}10.0 \% \\
6.0 \%\end{array}\right\} 16 \%$ & $\left.\begin{array}{r}10.5 \% \\
3.5 \%\end{array}\right\} 14 \%$ \\
\hline $\begin{array}{l}\text { Total no. of } \\
\text { eyes }\end{array}$ & 59 & 51 & 28 \\
\hline
\end{tabular}


infection were absent. A shallow or flat anterior chamber was present at first dressing in 4 eyes $(6.8 \%)$, associated with a choroidal detachment, but only in 2 cases did it persist more than 3 days. (A flat anterior chamber at 3 days was noted in 3\% of trabeculectomies by Ridgway et al.). ${ }^{1}$ Six eyes had a severe postoperative uveitis, but 4 of these had secondary glaucoma with pre-existing uveitis.

Postoperative ocular hypertension was present in 11 eyes $(18.6 \%)$, but this settled rapidly in all but 2 cases. The latter both had secondary glaucoma, and in 1 of these an iris prolapse developed.

The $25 \%$ incidence of hyphaema was almost double the rate quoted for simple trabeculectomy by Ridgway et al. ${ }^{1}$ but was consistent with other studies of the combined operation. ${ }^{56}$ The hyphaemata all resolved rapidly without complication.

\section{VISUAL RESULTS}

Only 29 out of 59 eyes $(49 \%)$ achieved a corrected visual acuity of $6 / 12$ or better. The main factor accounting for failure to achieve this level of vision was glaucomatous visual damage in 21 out of the 59 eyes $(35 \%)$. Senile macular degeneration and diabetic maculopathy also contributed.

Apart from those eyes with advanced glaucomatous visual damage 29 out of 38 eyes $(76 \%)$ achieved 6/12 vision or better; if those eyes with glaucoma secondary to uveitis are also excluded, 25 out of 30 eyes $(83 \%)$ achieved $6 / 12$ vision or better. These results compare favourably with those obtained in a recent study of intracapsular cataract extraction in nonglaucomatous eyes. ${ }^{9}$

The degree of astigmatism is comparable to that obtained for simple cataract extraction by the limbal approach.

\section{LATE POSTOPERATIVE COMPLICATIONS}

Only 1 eye $(1 \cdot 7 \%)$ has developed a retinal detachment; bullous keratopathy from endothelial decompensation has not occurred, These results compare favourably with those of routine intracapsular cataract extraction. One patient with chronic angle-closure glaucoma subsequently developed uncontrollable neovascular glaucoma, and $27 \%$ of the eyes with secondary glaucoma went on to phthisis bulbi.

GLAUCOMA CONTROL

Overall control of intraocular pressure (less than $23 \mathrm{mmHg}$ ) was achieved in $91.5 \%$ at 6 months, $84 \%$ at 1 year, and $86 \%$ at 2 years. These results compare favourably with previous studies of trabeculectomy alone. Ridgway et al..$^{1}$ quoted $92 \%$ controlled in a 3-18 month follow-up, while Wilson ${ }^{3}$ quoted $85 \%$ controlled at 1 year. However, the proportion of patients requiring additional medical treatment to ensure control of intraocular pressure rose from $15 \%$ at 6 months to $21.5 \%$ at 1 year and $32 \%$ at 2 years. In Wilson's study $328.7 \%$ required additional therapy at 1 year.

The efficacy of control is related to the diagnostic group and whether the glaucoma was controlled preoperatively or not. Fewer of those patients who were controlled preoperatively required any postoperative medication.

As regards the diagnostic categories, the patients with secondary glaucoma fared conspicuously worse than those with primary glaucoma. Three out of the 11 eyes with secondary glaucoma became phthisical, but 5 were controlled at 1 year, and 4 of the 7 eyes that have been followed up for 2 or more years are still controlled.

The outcome for both chronic open-angle glaucoma and chronic closed-angle glaucoma was excellent; both groups had control rates of over $90 \%$ at 1 and 2 years' follow-up. However, more patients with open-angle glaucoma required additional medication to achieve control.

The fact that an increasing percentage of patients require additional therapy to maintain control as the postoperative follow-up extends is very important, and indicates a need for close supervision of these patients. In these 2 groups only 2 eyes required additional therapy between 6 months and 1 year, but subsequently a further 6 eyes required additional medical treatment between 12 and 22 months postoperatively. In a number of these patients glaucomatous visual damage had progressed when failure of control was not detected early. These patients need more frequent follow-up than medically controlled glaucoma patients. This should be at 3-monthly intervals for the first 2 years after surgery.

\section{Conclusions}

The combined operation of trabeculectomy and cataract extraction gives results comparable to those obtained for the separate procedures, if allowance is made for the pre-existing glaucomatous visual damage. It is both a safe and effective procedure for patients with cataract and either open- or closedangle glaucoma. The value of this operation in cataract and secondary glaucoma associated with uveitis is doubtful. The importance of frequent follow-up in the postoperative period has been emphasised.

I thank the consultant surgeons of the Birmingham and Midland Eye Hospital for permission to study their patients, and Miss Eagling for her helpful advice and encouragement. 


\section{References}

1 Ridgway AE, Rubinstein K, Smith VH. Trabeculectomy: a study of 86 cases. Br J Ophthalmol 1972; 56: 511-6.

2 Watson PG, Barnett F. Effectiveness of trabeculectomy in glaucoma. Am J Ophthalmol 1975; 79: 831-45.

3 Wilson P. Trabeculectomy: a long term follow-up. $\mathrm{Br} J$ Ophthalmol 1977; 61: 535-8.

4 Thyer AW, Wilson P. Trabeculectomy. Br J Ophthalmol 1972; 56: 37-40.

5 Eustace P, Harun AQS. Trabeculectomy combined with cataract extraction. Trans Ophthalmol Soc UK 1974; 94: 1058-63.

6 Witmer R, Rohen JW. Combined cataract glaucoma operation. Trans Ophthalmol Soc UK 1976; 96: 256-61.

7 Watson PG. Trabeculectomy. Trans Ophthalmol Soc UK $1969 ; 89$ : 523-6.

8 Duke-Elder S. System of Ophthalmology. London: Kimpton, 1969: 11: 277-86.

9 Jaffe NS, Eicherbaum DM, Clayman HM, Light DS. A comparison of 500 Binkhorst implants with 500 routine intracapsular cataract extractions. $A m J$ Ophthalmol 1978; 85: 24-7. 